\title{
On a problem of moments
}

by

S. ROLEWICZ (Warszawa)

Let $X$ and $Y$ be two real Banach spaces. Let $A$ be a continuous linear operator mapping $X$ into $Y$. Let us consider the equation

$$
A(u)=c .
$$

We are looking for the minimum norm solution of equation (1), i.e. for such a solution $u_{0}$ of equation (1) that

$$
u_{0}=\inf \{\|u\|: A(u)=c\} .
$$

The problem considered in question often occurs in the theory of control. It has been considered for finite-dimensional $Y$ by many authors (see for example [3] and [4]). Obviously, in this case the operator $A(u)$ can be considered as a finite system of linear functionals

$$
A(u)=\left\{A_{1}(u), \ldots, A_{n}(u)\right\}
$$

and $c$ as a system of numbers

$$
c=\left\{c_{1}, \ldots, c_{n}\right\}
$$

The main theorem in this case is

$$
\inf \{\|u\|: A(u)=c\}=\sup _{\lambda_{1}, \ldots, \lambda_{n}} \inf \left\{\|u\|: \sum_{i=1}^{n} \lambda_{i} A_{i}(u)=\sum_{i=1}^{n} \lambda_{i} c_{i}\right\} .
$$

The case $X=L^{p}, 1<p \leqslant+\infty$, and $Y=l^{p}$ has been considered by Butkowski [2]. The method he used is the following: since $c \in l^{p}, c$ $=\left\{c_{1}, \ldots, c_{n}, \ldots\right\}$ and the operator $A$ can be described as a sequence of functionals. The idea is to approximate equation (1) by a finite system of functional equations and then, using weak compactness or weak* compactness, to prove the existence of a minimum norm solution of equation (1).

In this note a generalization of formula (3) for infinite-dimensional Banach spaces will be given. The paper contains also applications of this generalization to the theory of control. 
THEOREM. Let $X$ and $Y$ be two real Banach spaces. Let $A$ be a continuous linear operator mapping $X$ into $Y$. Let the image $I$ of the unit ball

$$
K=\{x \in X:\|x\| \leqslant 1\}
$$

by the operator $A$ be a closed set. Let $c$ be a fixed element in $Y$. Let there exist a solution of equation $A(u)=c$. Then

$$
\text { (4) } \quad \inf \{\|u\|: A(u)=c, u \in X\}=\sup _{F_{\epsilon} \bar{X}^{*}} \inf \left\{\|u\|: F(A(u))=H^{\prime}(c)\right\} \text {, }
$$

where as usual $Y^{*}$ denotes the conjugate space to the space $Y$, i.e. the space of all continuous linear functionals defined on $Y$.

Proof. Obviously, each solution of equation (1) is simultaneously a solution of the equation

Therefore

$$
F(A(u))=F(c) .
$$

where

$$
\begin{aligned}
& a=\inf \{\|u\|: A(u)=c\}, \\
& b=\sup _{\boldsymbol{F}_{\mathbf{e}} \bar{Y}^{*}} \inf \{\|u\|: F(A(u))=F(c)\} .
\end{aligned}
$$

Now we shall show that conversely also

$$
a \leqslant b \text {. }
$$

In fact, let us suppose that (8) does not hold, i.e. that

$$
a>b \text {. }
$$

Formula (9) implies that $c$ does not belong to $b I$. But under the assumption the set $b \Gamma$ is closed. Therefore the theorem on the separation implies that there are a positive number $\varepsilon$ and a linear continuous functional $F_{1}$ such that

$$
\text { (10) } \quad F_{1}(c)=1
$$

and

(11)

Hence

$$
F_{1}(x)<1-\varepsilon \quad \text { for } x \in b \Gamma \text {. }
$$

$$
\inf \left\{\|u\|: F^{\prime}(A(u))=F_{1}(c)=1\right\} \geqslant \frac{b}{1-\varepsilon}
$$

and this leads to a contradiction of the definition of $b$, q.e.d.

Remark 1. Let us remark that for finite-dimensional $Y$ the assumption that the set $\Gamma$ is closed is not necessary, since in this case formula (9) implies that $c \notin b \bar{T}$.
Remark 2. The theorem is also true if we replace Banach norms by Minkowski norms, i.e. norms which are not homogeneous but only positive homogeneous.

CoROLLARY. Let us assume that the assumptions of the theorem are satisfied and $\operatorname{dim} Y<+\infty$. Let us assume that there is a functional $F_{0}$ such that

$$
\inf \{\|u\|: A(u)=c\}=\inf \left\{\|u\|: F_{0}(A(u))=F_{0}(c)\right\} .
$$

Let us assume that the equation

$$
F_{0}(A(u))=F_{0}(c)
$$

has a unique minimal norm solution $u_{0}$. Then $u_{0}$ is the minimum norm solution of equation (1) also.

Pro of. Since $T$ is finite-dimensional and closed, it is compact. Since $\inf \{\|u\|: A(u)=c\}$ is finite, there is a minimum norm solution $u_{1}$ of equation (1). Obviously,

$$
F_{0}\left(A\left(u_{1}\right)\right)=F_{0}(0)
$$

Then formula (13) implies that $u_{1}$ is the minimum norm solution of equation (14). But equation (14) has a unique solution $u_{0}$. Therefore $u_{1}=u_{0}$, q.e.d.

If the set $T$ is not closed, the corollary does not hold even if $Y$ is a two-dimensional space, as is shown by the following

Example. Let $X$ be a subspace of the space $L^{1}[0,1]$ consisting of all functions constant on the interval $\left(\frac{1}{4}, \frac{3}{4}\right)$. Let $Y$ be a two-dimensional space. Let

$$
A(u)=\left\{F_{1}(u), F_{2}(u)\right\},
$$

where the functionals $F_{1}$ and $F_{2}$ are of type

$$
F_{i}(u)=\int_{0}^{1} f_{i}(t) u(t) d t, \quad i=1,2,
$$

and

$$
\begin{gathered}
f_{1}(t)=\left\{\begin{array}{lll}
4 t & \text { for } & 0 \leqslant t<1, \\
\frac{1}{2} & \text { for } & \frac{1}{4} \leqslant t<\frac{3}{4} \\
0 & \text { for } & \frac{3}{4} \leqslant t \leqslant 1
\end{array}\right. \\
f_{2}(t)=f_{1}(1-t) .
\end{gathered}
$$

By a simple calculation we obtain

$$
\Gamma=\{(x, y):|x|+|y|<1\} \cup\left( \pm \frac{1}{2}, \pm \frac{1}{2}\right) .
$$


Let $c=\left(\frac{1}{3}, \frac{2}{3}\right)$. Then there is a functional $F_{0}$ satisfying (13) and it is given by the formula

$$
F_{0}((x, y))=x+y
$$

Then equation (14) has a unique solution $\left(\frac{1}{2}, \frac{1}{2}\right) \neq\left(\frac{1}{3}, \frac{2}{3}\right)$.

Now we shall apply the theorem to a problem of the theory of control. Let us consider the following system of strings:

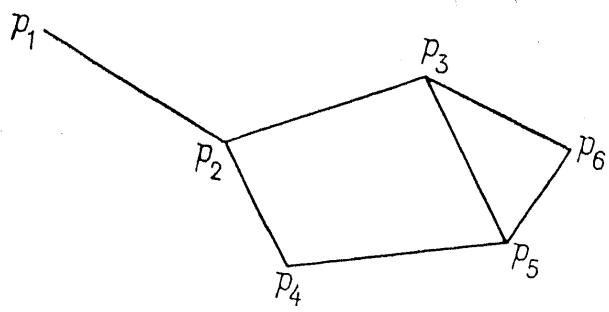

Let us consider only perpendicular vibrations. Let the state of the system be described by the perpendicular deviation $Q(x, t)$ at the point $x$ and at the moment $t$. Let us control our system by perpendicular deviations $\left(u_{1}(t), \ldots, u_{n}(t)\right)$ at the ends of the strings $p_{1}, \ldots, p_{n}$.

We shall consider the following minimum time problem for the system. Suppose we are given an initial state, i.e. the initial position $Q(x, 0)=Q_{0}(x)$ and the initial speed

$$
\left.\frac{\partial Q(x, t)}{\partial t}\right|_{t=0}=Q_{0}(x)
$$

We are looking for a minimum time $T$ and control $u(t)$ bringing the system to rest, i.e. for such a control $u(t)=\left(u_{1}(t), \ldots, u_{n}(t)\right)$ that

and

$$
Q(x, T)=0
$$

$$
\left.\frac{\partial Q(x, t)}{\partial t}\right|_{t=T}=0
$$

This problem has been considered for one string controlled by one end by Butkowski [2]. Butkowski has reduced the problem to the solving the infinite system of integral equations

$$
\begin{aligned}
& \int_{0}^{T} \sin k \pi \frac{a}{S} t u(t) d t=a_{l k}, \quad \\
& \int_{0}^{T} \cos k \pi \frac{a}{S} t u(t) d t=b_{k},
\end{aligned}
$$

where $S$ is the length of the string, $a$ is the coefficient of wave equation, the numbers $a_{k}$ and $b_{k}$ are defined by $Q_{0}(x)$ and $\dot{Q}(x)$ and

$$
\sum_{k=1}^{\infty} a_{k}^{2}+b_{k}^{2}<+\infty
$$

Using the same method we find that the minimum time problem for the system in question also can be reduced to the solving the system

$$
\begin{gathered}
\int_{0}^{T}\left[\sin \pi \frac{a_{i, j}}{S_{i, j}} l e t u_{i}(t)+\sin \pi\left(\frac{a_{i, j}}{S_{i, j}}-1\right) k t u_{j}(t)\right] d t=a_{k}^{i, j}, \\
\int_{0}^{T}\left[\cos \pi \frac{a_{i, j}}{S_{i, j}} k t u_{i}(t)+\cos \pi\left(\frac{a_{i, j}}{S_{i, j}}-1\right) k t u_{j}(t)\right] d t=b_{k}^{i, j} \\
(k=1,2, \ldots,(i, j) \in A),
\end{gathered}
$$

where $S_{i, j}$ is the length of the string connecting points $p_{i}$ and $p_{j}, a_{i, j}$ is the coefficient of the wave equation of this string, $A$ is the set of pairs of positive integers such that there is a string connecting $p_{i}$ with $p_{j}$, the coefficients $a_{k}^{i, j}$ and $b_{k}^{i, j}$ are determined by $Q_{0}(x)$ and $\dot{Q}(x)$ and

$$
\sum_{(i, j) \in A} \sum_{k=1}^{\infty}\left(a_{k}^{i, j}\right)^{2}+\left(b_{k}^{i, j}\right)^{2}<+\infty .
$$

Let us assume that

$$
a_{i, j} / S_{i, j}=\pi
$$

Then the system of equations (25) gives the system

$$
\begin{aligned}
& \int_{0}^{T}\left[\sin k t \cdot u_{i}(t)+\sin k(t-\pi) u_{j}(t)\right] d t=a_{k}^{i, j}, \\
& \int_{0}^{T}\left[\cos k t \cdot u_{i}(t)+\cos k(t-\pi) u_{j}(t)\right] d t=b_{k}^{i, j} \\
&(k=1,2, \ldots,(i, j) \epsilon A) .
\end{aligned}
$$

Situations in engineering imply constraints of different types for $u(u)=\left(u_{1}(t), \ldots, u_{n}(t)\right)$. Let us assume that those constraints are of the following type. Given a function $H\left(z_{1}, \ldots, z_{n}\right)$ defined for non-negative $z_{1}, \ldots, z_{n}$. Let $H$ be a continuous function. Let $H(0, \ldots, 0)=0$ and let

$$
H\left(z_{1}+z_{1}^{\prime}, \ldots, z_{n}+z_{n}^{\prime}\right) \leqslant H\left(z_{1}, \ldots, z_{n}\right)+H\left(z_{1}^{\prime}, \ldots, z_{n}^{\prime}\right) .
$$

Let us suppose that $u_{i}(t) \in L^{p_{i}}[0, T], 1<p_{i} \leqslant+\infty$. Let the constraints be of type
$\left(27^{\prime}\right)$
$|u| \leqslant M$, 


\section{where}

$$
|u|=H\left(\left\|u_{1}\right\|, \ldots,\left\|u_{n}\right\|\right) .
$$

Let us consider the product $X$ of the spaces $L^{p_{i}}[0, T], i=1, \ldots, n$ :

$$
X=L^{p_{1}}[0, T] \times \ldots \times L^{p_{n}}[0, T] .
$$

Obviously, $X$ is a Banach space with respect to the norm $|u|$ defined by formula (28).

Using the classical technique of the theory of control we can reduce the minimum time problem to the minimum norm problem (see [2], [3], [4] and [6]), i.e. we are looking for an element with the minimal norm satisfying $\left(25^{\prime}\right)$.

Obviously equations $\left(25^{\prime}\right)$ can be considered as an operator equation

$$
A(u)=c,
$$

where $A$ is an operator mapping $X$ into $l^{2}$.

Simultaneously with the space $X$ we can consider a subspace $X_{p} \subset X$ constituted by periodic functions of the period $2 \pi$ belonging to $X$. Let us consider the minimum problem in the space $X_{p}$. Obviously

(30) $\quad \inf \{|u|: u \in X, A(u)=c\} \leqslant \inf \left\{|u|: u \in X_{p}, A(u)=c\right\}$.

We shall show that in fact we have equality there.

Our further considerations are based on the following lemmas.

LEMMA 1. Let $F$ be a functional defined on $X$ by a periodic function $f(t)=\left(\left(f_{1}(t), \ldots, f_{n}(t)\right)\right.$ with the period $2 \pi$ by the formula

$$
F(u)=\int_{0}^{T}\left[f_{1}(t) u_{1}(t)+\ldots+f_{n}(t) u_{n}(t)\right] d t .
$$

Then

$$
\sup _{\substack{u \in \mathbb{X} \\\|u\| \leqslant 1}}\left|F^{\prime}(u)\right|=\left\|T^{\prime}\right\|
$$

Proof. Let $u(t)=\left(u_{1}(t), \ldots, u_{n}(t)\right) \in X$. Since $u_{i}(t) \in L^{p_{i}}[0, T]$, there is a periodic function $u_{i}^{p}(t)$ such that $\left\|u_{i}\right\|=\left\|u_{i}^{p}\right\|$ and

$$
\int_{0}^{T} f_{i}(t) u_{i}(t) d t \leqslant \int_{0}^{T} f_{i}(t) u_{p}^{i}(t) d t
$$

(in fact we can put

$$
u_{i}^{p}(t)=\frac{\left\|u_{i}\right\|}{\left\|f_{i}\right\|^{\alpha_{i}}}\left|f_{i}(t)\right|^{1-q_{i}} \operatorname{sign} f_{i}(t),
$$

where $\left.q_{i}=p_{i} /\left(p_{i}-1\right)\right)$.
Let us write $u^{p}(t)=\left(u_{1}^{p}(t), \ldots, u_{n}^{p}(t)\right)$. Then formula (33) implies

$$
F\left(u^{p}\right) \geqslant F(u) \text {. }
$$

Formula (32) trivially follows from formula (34) and the definition of the norm of a functional.

LEMCMA 2. The set $\Gamma=A(K)$, where $K$ is a unit ball in the space $X$ and $A$ is the operator induced by formula $\left(25^{\prime}\right)$, is closed.

Proof. The space $X$ can be considered as a space conjugate to the space

$$
X_{0}=L^{q_{1}}[0, T] \times \ldots \times L^{q_{n}}[0, T],
$$

where $q_{i}=p_{i} /\left(1-p_{i}\right)$ if $p_{i}<+\infty$ and $q_{i}=1$ if $p_{i}=+\infty$, with the respective norm. The space $X_{0}$ is separable. Hence the unit ball $K$ in the space $X$ is weak ${ }^{*}$ compact. The operator $A$ is weak* continuous. Therefore the set $\Gamma$ is weak* compact, whence closed.

LEMma 3. The set $\Gamma_{p}=A\left(K_{p}\right)$, where $K_{p}$ is a unit ball in the space $X_{p}$, is closed.

The proof is similar to the proof of Lemma 2 .

Proposition 1. We have

$$
\inf _{u \in X_{p}}\{\|u\|: A(u)=c\}=\inf _{u \in X}\{\|u\|: A(u)=c\} .
$$

Proof. For an arbitrary functional $F \in Y^{*}=l^{2}$ the functional $A F(u)$ $=F(A(u))$ is of type (31), where

$$
\text { (37) } \quad f_{i}(t)=\sum_{k=1}^{\infty} \alpha_{k}^{i} \sin k t+\beta_{k}^{i} \cos k t+\gamma_{k}^{i} \sin k(t-\pi)+\delta_{k}^{i} \cos k(t-\pi)
$$

are periodic functions of the period $2 \pi$. Therefore Lemma 1 implies

$$
\text { (38) } \quad \inf _{u \in X_{p}}\{\|u\|: F(A(u))=F(c)\}=\inf _{u \in X}\{\|u\|: F(A(u))=F(c)\} \text {. }
$$

Lemmas 2 and 3 imply that the theorem is applicable to both spaces, $X$ and $X_{p}$. Hence formula (36) follows from formula (38), q.e.d.

Proposition 2. If there is a solution of the equation $A(u)=c$, i.e. if the system is controllable with respect to the point $c$, then there is also a periodic minimum norm solution belonging to $X_{p}$ of the equation in the space $X$.

Proof. Basing ourselves on Proposition 1 we can find a sequence $u_{n} \in X_{p}$ such that $A\left(u_{n}\right)=c$ and

$$
\lim \left|u_{n}\right|=\inf \{|u|: u \in X, A(u)=c\} .
$$


The set $X_{m}$ is weak ${ }^{*}$ closed. The set $A^{-1}(c)$, as inverse image of a point by a weak* continuous operator, is also weak* closed. Therefore for all $r>a$ the set

$$
K_{r}^{0}=\left\{u \in X_{p} \cap A^{-1}(c):|u|<r\right\}
$$

is weak* compact. This implies that there is a weak ${ }^{*}$ limit $u_{0}$ of the sequence $u_{n}$ and that

$$
\left|u_{0}\right|=\inf \{|u|: \dot{A}(u)=c\} .
$$

Since $A$ is weak* continuous, $A\left(u_{0}\right)=c$, q.e.d.

Propositions 1 and 2 can easily be extended to all systems for which the control problem is reduced to the solving a countable number of equations

$$
\int_{0}^{T} \sum_{j=1}^{n_{i}} f_{i, j}(t) u_{i j}(t)=a_{i},
$$

where all functions $f_{i, j}(t)$ are periodic with the same period, $u \in X,\left(a_{i}\right) \in l^{p}$.

For example, Propositions 1 and 2 hold also for a system similar to those described above but controlled by the second derivatives of deviations (cf. paper [5] for one string).

The space $X$ can also be replaced by more general space namely by the space

$$
X_{1}=L_{E_{1}}^{p_{1}}[0, T] \times \ldots \times L_{\mathbb{E}_{n}}^{p_{n}}[0, T]
$$

where $E_{i}$ are $k_{i}$-dimensional Minkowski spaces with the norm \|\|$_{i}$ ani

$$
L_{E_{i}}^{p_{i}}[0, T]=\left\{u(t)=\left(u_{1}(t), \ldots, u_{n}(t)\right):|u|_{i}<+\infty\right\},
$$

where the norm $|u|_{i}$ is defined by the formula

$$
|u|_{i}=\left(\int_{0}^{T}\|u(t)\|_{i}^{p} d t\right)^{1 / p}
$$

(see [6] and [7]).

The norm in $X_{1}$ is defined in the similar way as in $\dot{X}$

\section{References}

[1] Н. И. Ахи езер и М. Г. Крейн, О некоторых вопросах теории моментов, Харьков 1938.

[2] А. Г. Бутковский, Теория оптималъного управления системами с разпределенными параметрами, Москва 1965.

[3] Н. Н. Крассовский, $K$ теории оптимальпого управленил, Автоматика и Телемеханика 18 (1957), вып. 11, p. 960-970.
[4] R. Kulikowski, Procesy optymalne $i$ adaptaeyjne w uktadach regulacji automatycznej, Warszawa - Wrocław 1965.

[5] K. Malanowski, On the optimal control of vibrating string, Archiwum Automatyki i Telemechaniki (in preparation).

[6] - i S. Rolewicz, Zastosowanie metody plaszczyzn podpierajacych do wyznaczania sterowania czasowo optymalnego, ibidem 10 (1965), p. 151-170.

[7] К. Малянов ский и С. Р олевич, Определение оптимального по быетрадейстөито управления линейлыми многомерными системами с помощью методов функционального анализа, Ж. выч. матем. и теор. физики 5 (1965), р. 242-251.

\section{INSTITUTE OF MATHEMATICS OF THE POLISH ACADEMY OF SCIENCES} INSTYTUT MATEMATYCZNY POLSKIET AKADEMTI NAUK

Reçu par la Rédaction le 9. 10. 1967 